\title{
Penile Degloving and Dorsal Dartos Flap Rotation Surgery in the Management of Severe Isolated Penile Torsion in a 6-Year-Old Boy
}

\author{
Zlatan Zvizdic ${ }^{1}$, Emir Milisic ${ }^{1}$, Semir Vranic ${ }^{2, *}$
}

\begin{abstract}
Penile torsion is a rare congenital anomaly that is usually characterized by a counterclockwise rotation of the penile shaft or glans. form of penile degloving and dorsal dartos flap rotation surgery.

\section{KEYWORDS}

isolated penile torsion; children; surgery; penile degloving; dorsal dartos flap rotation

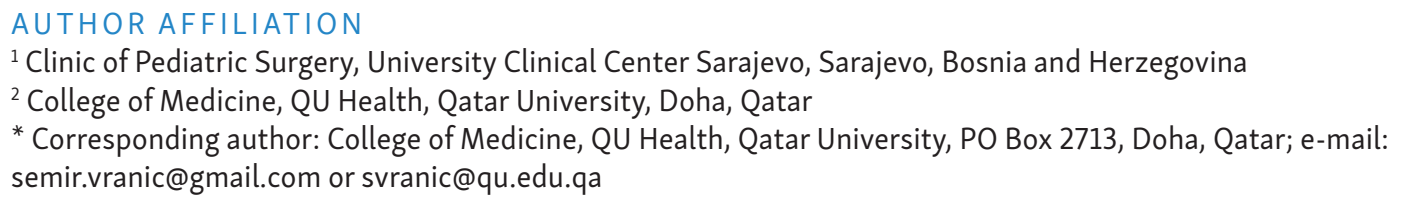
Although several surgical techniques for its correction have been proposed, the consensus of choosing the most efficient technique remains controversial. Herein, we report our operational approach that successfully corrected a severe (>90 degrees) isolated penile torsion in the

Acta Medica (Hradec Králové) 2020; 63(1): 52-54 https://doi.org/10.14712/18059694.2020.16

(c) 2020 The Authors. This is an open-access article distributed under the terms of the Creative Commons Attribution License (http://creativecommons.org/licenses/by/4.0), which permits unrestricted use, distribution, and reproduction in any medium, provided the original author and source are credited. 


\section{INTRODUCTION}

Penile torsion is a rare congenital rotational defect of the penile shaft and glans on the longitudinal penile axis usually in a counterclockwise direction (1). Penile torsion is commonly seen in association with hypospadias or chordee while isolated penile torsion is rarely seen (2). Although the precise etiology of this anomaly is unclear, it is thought that penile torsion occurs because of the abnormality of the skin and dartos fascia attachment or abnormal development of the dartos fascia that causes disorientation of the penile shaft and corporeal rotation around its longitudinal axis (1). Recently, Zhou et al. proposed that the asymmetric development of the corpora cavernosa represented a major etiological factor of this anomaly (3). Regarding the degree of rotation, isolated penile torsion is divided into mild (<45 degrees), moderate (45-90 degrees) and severe (>90 degrees) forms (4). The precise incidence of isolated penile torsion is unknown but is believed to be in the range of 2-27\% (5-7). However, surgical correction is required in only $\sim 4 \%$ of patients (6).

Many operative techniques have been described for the correction of penile torsion including penile degloving and realignment technique, suturing the tunica albuginea to the pubic periosteum, dorsal dartos flap rotation, correction by mobilization of urethral plate and urethra, resection of Buck's fascia, modified Nesbit procedure, and diagonal corporal plication $(1,3,4,6,8-11)$. However, the consensus on the most efficient and appropriate technique is still missing.

Herein, we report our operational approach for correction of severe (>90 degrees) isolated penile torsion in the form of penile degloving and dorsal dartos flap rotation surgery.

\section{CASE REPORT}

A 6-year-old uncircumcised boy presented with isolated penile torsion. Physical examination showed $>90$ degrees penile torsion, directed in a counterclockwise fashion with spiral deviation of the penile median raphe (Figures 1A-D). The surgical correction of penile torsion was carried out under general anesthesia. A circumferential subcoronal incision was taken and the penile skin and dartos were degloved to the penile root with division of all adhesion tissues. To achieve an artificial erection, we used a normal saline solution through a butterfly needle into one corporal body. The dorsal dartos flap technique was composed of dissection of the dorsal penile skin and dorsal dartos flap creation, which was rotated around the side of the penile shaft opposite to the direction of penile rotation and attached to the ventral aspect of the penile shaft. The operative technique was completed by a simple rearrangement of the skin on the shaft of the penis (Figure 2A). This operative technique has led to a complete correction of penile torsion, which was demonstrated by the presence of slit of the urethral meatus in one line with scrotal raphe (Figure 2B). Urinary catheter was not used during and after the procedure and no complications were recorded. Postoperative course of the patient was uneventful.
One-year follow-up revealed a satisfactory correction of the abnormal rotation in our patient.

\section{DISCUSSION}

For a long time after initial description of penile torsion by Verneuil in 1857, there has not been a proper recommendation for its operative correction (12). Recently, several researchers recommended a penile degloving as an adequate surgical procedure for correcting mild penile torsion $(<45$ degrees) while in moderate and severe degrees of penile torsion, other operative techniques were suggested. These approaches may, however, be associated with significantly higher risk of postoperative complications (1, 3, 4, 6, 8-11).

The dorsal dartos flap, previously used to cover the suture line urethroplasty in hypospadia surgery, proved as an effective technique for moderate and severe penile torsion $(4,13,14)$. This technique was initially present-

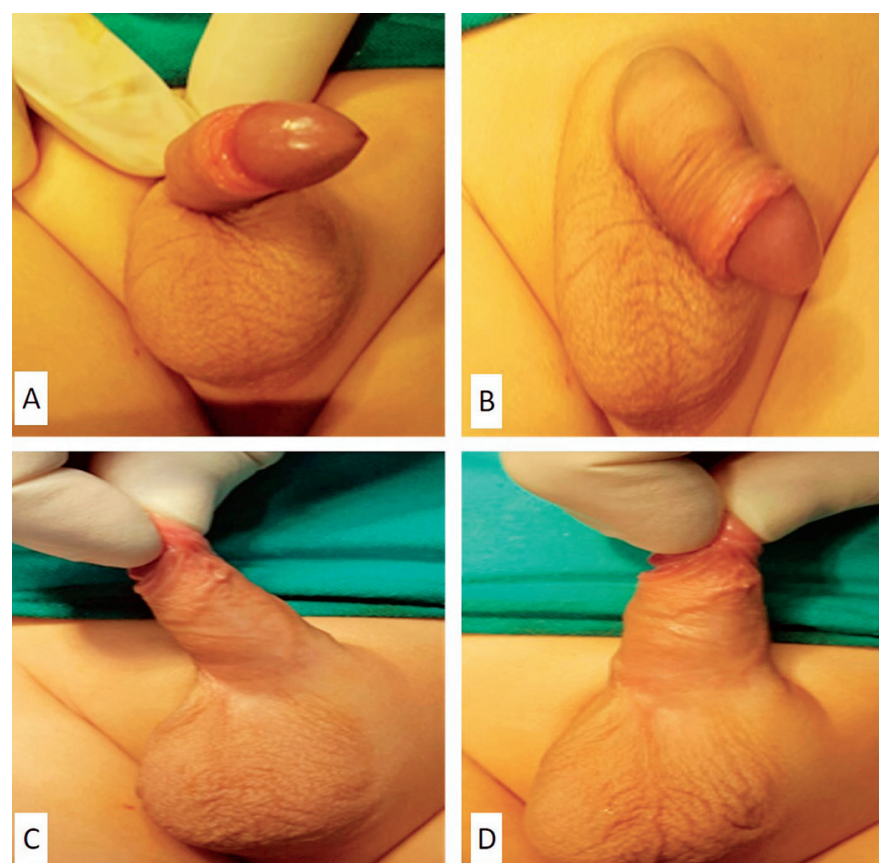

Fig. 1 (A-B): Isolated counterclockwise penile torsion (>90 degrees); (C-D): Median raphe pass in a spiral manner from the base of the penis ventrally and around the penile shaft.
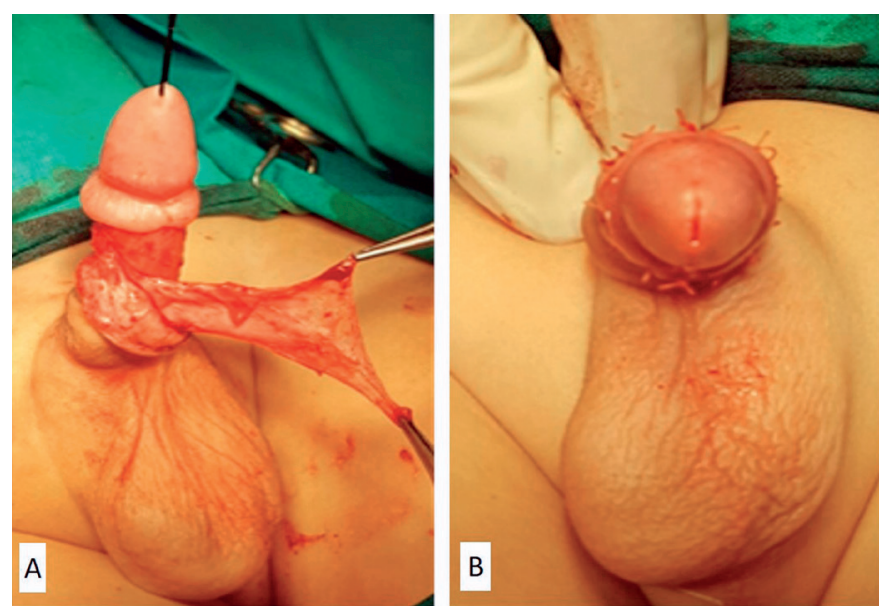

Fig. 2 (A): Intraoperative creation of dorsal dartos flap; (B): Postoperative view of complete correction of penile torsion. 
ed by Fisher and Park in 2004 and implied performing a complete degloving of the penis, mobilization of a wide, well-vascularized dorsal dartos flap, its rotation around the right side of the penile shaft and fixation to the ventral aspect, causing clockwise penile rotation (4). This operative technique is completed by a simple rearrangement of the skin on the shaft of the penis (4).

The reported success rate of this technique in the complete correction of penile torsion was $100 \%$ in the Fisher and Park series (4), 97\% in Marret et al. series (15), and only $64 \%$ in the Bauer and Kogan series (13). However, these authors found that $9 / 25$ patients with incomplete penile torsion correction had a residual torsion of $<10$ degrees, which did not require an additional operative treatment (13). All these studies concluded that dorsal dartos flap rotation technique provides excellent short-term results.

\section{CONCLUSIONS}

Based on our experience and previous data, we confirm that the dorsal dartos flap rotation techniq isa suitable approach for the treatment of moderate and severe forms of penile torsion. It is a safe procedure that is free of major complications.

\section{CONFLICT OF INTEREST}

Authors have no conflicts of interest to declare.

\section{REFERENCES}

1. Bar-Yosef Y, Binyamini J, Matzkin H, Ben-Chaim J. Degloving and rerealignment - simple repair of isolated penile torsion. Urology 2007; 69(2):369-71.

2. Elbakry A, Zakaria A, Matar A, El Nashar A. The management of moderate and severe congenital penile torsion associated with hypospadias: Urethral mobilisation is not a panacea against torsion. Arab J Urol 2013; 11(1): 1-7.

3. Zhou L, Mei H, Hwang AH, Xie HW, Hardy BE. Penile torsion repair by suturing tunica albuginea to the pubic periosteum. J Pediatr Surg 2006; 41(1): e7-9.

4. Fisher PC, Park JM. Penile torsion repair using dorsal dartos flap rotation. J Urol 2004; 171(5): 1903-4.

5. Sarkis PE, Sadasivam M. Incidence and predictive factors of isolated neonatal penile glanular torsion. J Pediatr Urol 2007; 3(6): 495-9.

6. Bhat A, Bhat MP, Saxena G. Correction of penile torsion by mobilization of urethral plate and urethra. J Pediatr Urol 2009; 5(6): 451-7.

7. Eroglu E, Gundogdu G. Isolated penile torsion in newborns. Can Urol Assoc J 2015; 9(11-12): E805-7.

8. Slawin KM, Nagler HM. Treatment of congenital penile curvature with penile torsion: a new twist. J Urol 1992; 147(1): 152-4.

9. Hsieh JT, Wong WY, Chen J, Chang HJ, Liu SP. Congenital isolated penile torsion in adults: untwist with plication. Urology 2002; 59(3): 438-40.

10. Azmy A, Eckstein HB. Surgical correction of torsion of the penis. $\mathrm{Br}$ J Urol 1981; 53(4): 378-9.

11. Snow BW. Penile torsion correction by diagonal corporal plication sutures. Int Braz J Urol 2009; 35(1): 56-9; discussion 7-9.

12. Verneuil M. Torsion congenitale du penis avec hypospadias. Bullerin de la Socete de Chirurgie de Paris 1857; 8: 68-70.

13. Bauer R, Kogan BA. Modern technique for penile torsion repair. J Urol 2009; 182(1): 286-90; discussion 90-1.

14. Aykac A, Baran O, Yapici O, Aygun BA, Aydin C, Cakan M. Penile degloving and dorsal dartos flap rotation approach for the management of isolated penile torsion. Turk J Urol 2016; 42(1): 27-31.

15. Marret JB, Ravasse P, Raffoul L, Rod J. The Fisher Technique for Correction of Penile Torsion in Children: Who Are the Candidates? Urology 2017; 104: 179-82.

\section{CONSENT}

The authors acknowledge the patient's family for consenting to the report of this illustrative case. 